\title{
Factors associated with dietary patterns among low-income adults
}

\author{
Diana Barbosa Cunha ${ }^{1}$, Rosely Sichieri ${ }^{2}$, Renan Moritz Varnier Rodrigues de Almeida ${ }^{3}$ \\ and Rosangela Alves Pereira ${ }^{1, *}$ \\ 'Departament of Nutrition, Federal University of Rio de Janeiro, Av. Carlos Chagas Filho 373, Bloco J $-2^{\circ}$ \\ andar - sala 10, Cidade Universitária, CEP 21941-902 Rio de Janeiro, RJ, Brazil: ${ }^{2}$ Department of \\ Epidemiology, University of the State Rio de Janeiro, Rio de Janeiro, RJ, Brazil: ${ }^{3}$ Biomedical Engineering \\ Program/COPPE/Federal University of Rio de Janeiro, Rio de Janeiro, RJ, Brazil
}

Submitted 31 December 2009: Accepted 18 November 2010: First published online 18 January 2011

\begin{abstract}
Objective: To describe the association of socio-economic, demographic and lifestyle characteristics with three eating patterns identified among low-income adults living in the Rio de Janeiro metropolitan area, Brazil.

Design: Data were obtained in a population-based cross-sectional study. The analysed patterns were: (i) 'Mixed', in which diverse foods had similar factor loadings; (ii) 'Western', which included items with high energy density; and (iii) 'Traditional', which relied in rice and beans, traditional staple foods in Brazil. Hierarchical logistic analysis was performed to estimate the association between the independent variables and each one of the dietary patterns. The variables that presented statistical significance $<0 \cdot 20$ in the univariate analysis ( $\chi^{2}$ test) were included in the multivariate models.

Setting: Duque de Caxias, a low-income area in the Rio de Janeiro metropolitan region, Brazil.

Subjects: Adults ( $n$ 1009) aged 20 to 65 years (339 men and 670 women).

Results: The 'Mixed' pattern was positively associated with smoking (OR $=1 \cdot 58$, $95 \%$ CI 1·00, $2 \cdot 48$ for current smoking $v$. those who never smoked). The 'Western' pattern was positively associated with family income (OR $=3 \cdot 00,95 \%$ CI $1 \cdot 81$, 4.97 for those with monthly per capita family income $\geq 1.0 v .<0.5$ times the official Brazilian minimum wage) and inversely associated with family food insecurity $(\mathrm{OR}=0 \cdot 55,95 \% \mathrm{CI} 0 \cdot 36,0 \cdot 84)$. The 'Traditional' pattern was associated with family food insecurity (OR $=1 \cdot 79$, $95 \%$ CI $1 \cdot 27,2 \cdot 51)$.

Conclusions: The results support previous findings relating improvement in economic conditions to reduced adherence to the traditional Brazilian food consumption pattern based on the combination of rice and beans.
\end{abstract}

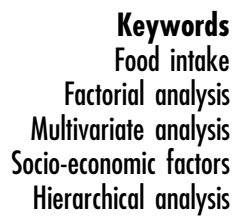

Keywords Food intake Multivariate analysis Hierarchical analysis
From the epidemiological point of view, diet represents a complex combination of exposures. However, epidemiological studies often fail in corroborating the effects observed experimentally for some dietary components. The conventional approach adopted in investigations on food consumption, which is centred on the evaluation of energy, nutrient or food intake as independent variables, does not allow one to consider the effect of the diet as a whole on the risk diseases, as the multicollinearity, confounding and interaction that may occur between the many dietary components are usually not appropriately taken into account ${ }^{(1,2)}$. For example, the association between the consumption of whole grains and the reduction in the risk for developing chronic diseases may be subject to confounding by the relationship between the use of unrefined products and the intakes of fruits, vegetables and fish ${ }^{(2-4)}$.

The identification of dietary patterns employing statistical procedures, such as principal component analysis and cluster analysis, has been considered as an alternative to overcome these limitations. Supposedly, dietary patterns illustrate the real situations of food availability and dietary practices of the study population ${ }^{(5,6)}$. Consequently, they facilitate the identification of subgroups that adopt eating habits compatible with the risk for or protection against diseases and provide reliable empirical support to the elaboration of dietary recommendations and guidelines ${ }^{(7-9)}$.

Three dietary patterns were identified among adults living in Duque de Caxias, a metropolitan area of Rio de 
Janeiro, Brazil ${ }^{(10)}$; one of these was characterized as the 'traditional' pattern which has also been identified in other studies carried out in this country ${ }^{(6,11,12)}$. In 1994-1995, Sichieri examined the association between dietary patterns and obesity in adults living in the city of Rio de Janeiro and also identified three main dietary patterns: 'mixed' (in which diverse food items showed similar factor loading), 'traditional' (characterized by the consumption of rice and beans) and 'Western' (characterized by the consumption of fats and soft drinks) ${ }^{(13)}$.

The traditional Brazilian food consumption pattern, centred around the consumption of rice and beans, has been considered to be protective due to its Fe and fibre contents and low energy density ${ }^{(10,13,14)}$.

The objective of the present study was to estimate the association between socio-economic, demographic and lifestyle factors and three dietary patterns in a low-income neighbourhood in the Rio de Janeiro metropolitan area.

\section{Methods}

The data refer to a population-based cross-sectional study, carried out in 2005 in the district of Campos Elíseos, in the municipality of Duque de Caxias, one of the poorest areas in the Rio de Janeiro metropolitan area, Brazil, which had 244000 inhabitants in the 2000 population census ${ }^{(15)}$.

The current analysis includes data from adults between 19 and 65 years old. A cluster sampling design with three selection stages was adopted for the selection of subjects. Primary sampling units (census sector) were the first stage of selection, households the second and adults the third; one adult was interviewed in each household. The sample design included the procedure of ranking the households according to income inside each census tract, allowing for sampling also according to this variable. Statistical tests indicated that data as well as the sample size were adequate for performing factorial analysis in the identification of dietary patterns ${ }^{(10)}$.

Data were obtained by means of interviews conducted in the households from May to December, 2005. All participants signed a free informed consent form, and the research was conducted within the standards demanded by the Declaration of Helsinki and approved by the Ethics Committee of the University of the State of Rio de Janeiro.

Food intake was estimated applying a semi-quantitative FFQ validated for the adult population of Rio de Janeiro ${ }^{(16)}$. The FFQ listed eighty-two food items, three options of portion size for each item and eight alternatives for reporting the frequency of food intake, which varied from 'never or almost never' to 'more than three times a day'.

To identify the dietary patterns, the food items listed in the FFQ were grouped into twenty-one food groups based on their nutritional characteristics and considering the reported intake frequency. Exploratory factor and principal component analysis were applied to derive dietary patterns. Orthogonal Varimax rotation of the factors was applied to improve the interpretation. Six solutions with eigenvalues $>1 \cdot 0$ were obtained, and the Cattell graph method $^{(17)}$ indicated that three patterns should be retained: (i) the 'Mixed' pattern, characterized by the consumption of cereals, fish and shrimp, leaves, vegetables, fruits, eggs, meats and caffeinated beverages; (ii) the 'Western' pattern, with high intakes of juices, cakes and cookies, soft drinks, milk and milk derivatives, sweets, snacks and fast foods; and (iii) the 'Traditional' pattern, characterized by the consumption of rice and beans, breads, sugar, sauces and fats. Those patterns together explained $35 \%$ of the total data variance.

\section{Hierarchical analysis}

Hierarchical analysis models were developed separately for each dietary pattern identified in order to estimate its association with the demographic, socio-economic and lifestyle variables. The factor scores associated with each pattern were categorized as lower than or equal to the median (reference category, codified as ' 0 ') or above the median (codified as ' 1 '). A factor score classified as 'above the median' was defined as adherence to a pattern.

In the theoretical model that oriented the hierarchical analysis, the socio-economic factors were considered as distal (group 1). In the second group were included variables related to the family characteristics (number of family members, presence of children and adolescents, sex of the household head, family food insecurity), and the third group was composed by the proximal variables related to lifestyle. The classification of the independent variables is described in Table 1.

The association between the independent and the dependent variables was tested in univariate analysis using the $\chi^{2}$ test, selecting for the hierarchical analysis those with a significance level $<0 \cdot 20$ in order to avoid the exclusion of potentially important variables. The hierarchical model was then developed using logistic regression analysis, considering significance levels $<0 \cdot 10$ for the maintenance of variables in the model. Age, sex and skin colour were maintained in the models as they were considered important confounding variables.

The first hierarchical level included in the model was composed by the socio-economic factors that presented statistical significance in the univariate analysis. In the second step of the analysis, the factors referring to family and household were included and their effects verified in the presence of the remaining factors from the previous level (those that presented $P<0 \cdot 10$ ). The same procedure was applied for including the third group of variables (those related to lifestyle). These approaches guaranteed control by variables from the previous groups. The final estimator for the effect of distal variables was the one observed before the introduction of the proximal variables, while estimators of the effect of the 
Table 1 Variables included in the theoretical model of hierarchical analysis analysing factors associated with dietary patterns in Brazilian adults

\begin{tabular}{|c|c|}
\hline Variable & Categories \\
\hline \multicolumn{2}{|l|}{ Group 1: Socio-economic factors } \\
\hline Education (years of study) & $\leq 4 ; 5-7 ; 8-10 ; \geq 11$ \\
\hline Working at the time of the survey? & Yes; no \\
\hline Monthly per capita family income & $\begin{array}{l}<0.5 \text { times minimum wage; } 0.5-1 \cdot 0 \text { times minimum wage; } \geq 1 \cdot 0 \\
\text { times minimum wage (note: the official Brazilian minimum } \\
\text { wage at the time of survey was about } \$ \text { US } 120 \cdot 00 \text { ) }\end{array}$ \\
\hline \multicolumn{2}{|l|}{ Group 2: Factors regarding the family and the household } \\
\hline Number of household members & $1-2 ; 3-5, \geq 6$ \\
\hline $\begin{array}{l}\text { Presence of children (up to } 5 \text { years) and/or adolescents } \\
\text { (12 to } 18.9 \text { years) }\end{array}$ & Yes; no \\
\hline Sex of household head & Male; female \\
\hline $\begin{array}{l}\text { Family food insecurity (based on the Brazilian scale of food } \\
\text { insecurity - EBIA) }\end{array}$ & $\begin{array}{l}\text { Yes (any degree of family food insecurity: mild, moderate, } \\
\text { severe); no }\end{array}$ \\
\hline Marital status of respondent & Single; married; divorced or widow/widower \\
\hline \multicolumn{2}{|l|}{ Group 3: Variables related to lifestyle } \\
\hline Smoking habits & Current smoker; ex-smoker; never smoked \\
\hline $\begin{array}{l}\text { Alcoholic beverage consumption (frequency of drinking in } \\
\text { the last year according to information reported in the FFQ) }\end{array}$ & $\begin{array}{l}\text { No report; }<1 \text { time/week, } 1-3 \text { times/week; } 4-5 \text { times/week; } \geq 6 \\
\text { times/week }\end{array}$ \\
\hline $\begin{array}{l}\text { Physical activity (considering leisure (yes/no), working } \\
\text { (mild, moderate, severe), domestic (yes/no) and } \\
\text { locomotion (yes/no) physical activity) }\end{array}$ & $\begin{array}{l}\text { Sedentary (reporting mild working physical activity and no leisure, } \\
\text { domestic or locomotion physical activity); mild (reporting mild } \\
\text { working activity and one of the other types of physical activity); } \\
\text { moderate (reporting moderate working activity and one or two } \\
\text { of the other types of physical activity); severe (intense working } \\
\text { activity and including at least one type of physical activity) }\end{array}$ \\
\hline \multicolumn{2}{|l|}{ Controlling variables } \\
\hline Age group (years old) & $19-30 ; 31-40 ; 41-50 ; 51-65$ \\
\hline Skin colour (evaluated according to the interviewer) & White; black; mixed \\
\hline Sex of the respondent & Male; female \\
\hline
\end{tabular}

proximal variables were observed after the introduction of the distal variables in the models, with the exclusion of variables with $P>0 \cdot 10$. Odds ratios and the respective $95 \%$ confidence intervals were estimated. The data were analysed using the SPSS statistical software package version 16•0 (SPSS Inc., Chicago, IL, USA).

\section{Results}

One thousand two hundred and fifty-three individuals were interviewed, of whom $222(17 \cdot 7 \%)$ reported implausible energy intake (below $2093 \mathrm{~kJ} / \mathrm{d}$ ( $n$ 5) or above $25121 \mathrm{~kJ} / \mathrm{d}$ ( $n$ 217)) and were excluded. Also excluded were twentytwo individuals with incomplete data on other variables. Analysis was done for 1009 individuals (males: 34\%, n 339; females: $66 \%, n$ 670). The mean age was 39 (sD 12) years, no significant difference was observed in the mean age according to sex $(P=0 \cdot 73$; Student's $t$ test $)$.

The results of the univariate analysis are summarized in Table 2. In short, all socio-economic variables were associated $(P<0 \cdot 20)$ with the 'Mixed' and 'Western' patterns. The sex of the household head and all lifestyle variables were also related to the 'Mixed' pattern. The number of household members, presence of children in the household and family food insecurity are the family variables that were associated with the 'Western' pattern; the only lifestyle variable associated with the 'Western' pattern was smoking. The 'Traditional' pattern was associated with the following family variables: working activity, number of household members, sex of the household head and family food insecurity; additionally, it was associated with the lifestyle variables of smoking, physical activity and alcoholic beverage consumption.

In the multivariate hierarchical analysis, it was observed that smokers presented adherence to the 'Mixed' pattern. Having a monthly per capita family income higher than 0.5 times the official Brazilian minimum wage (at the time of the study this value corresponded to \$US 60.00) had a direct association with adherence to the 'Western' pattern; nevertheless, belonging to families that reported food insecurity was associated with reduced adherence to this pattern. An increased adherence to the 'Traditional' pattern was observed for those living in households with food insecurity (Table 3).

\section{Discussion}

The present analysis described the association of socioeconomic, demographic and lifestyle characteristics with three eating patterns identified among low-income adults living in the Rio de Janeiro metropolitan area, Brazil. The results showed that even small increases in income are related to increased adherence to the 'Western' pattern, even though the mean income in this area is very low compared 
Table 2 Association between demographic, socio-economic and lifestyle factors and dietary patterns among adults ( $n$ 1009), Duque de Caxias, Rio de Janeiro, Brazil, 2005

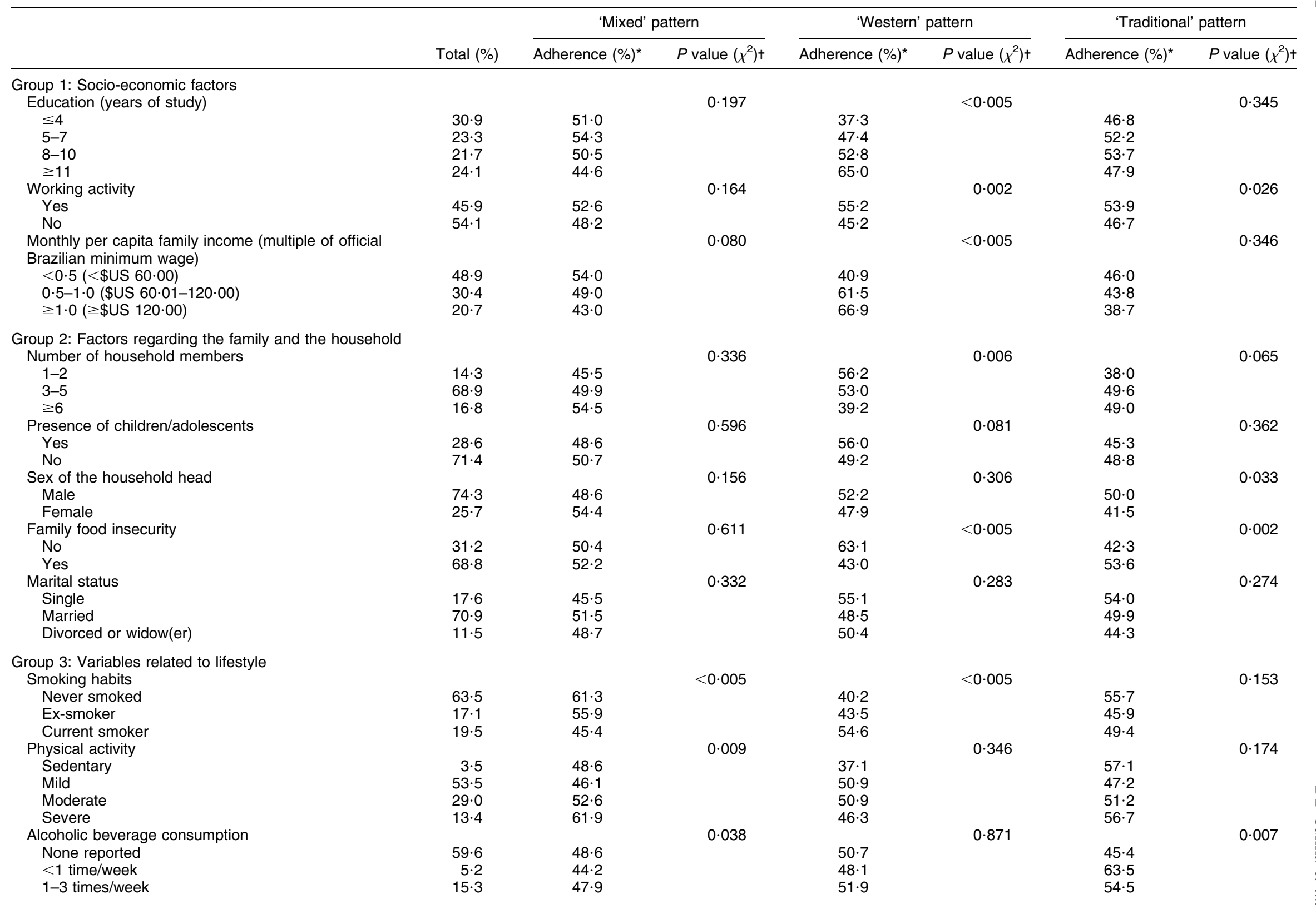




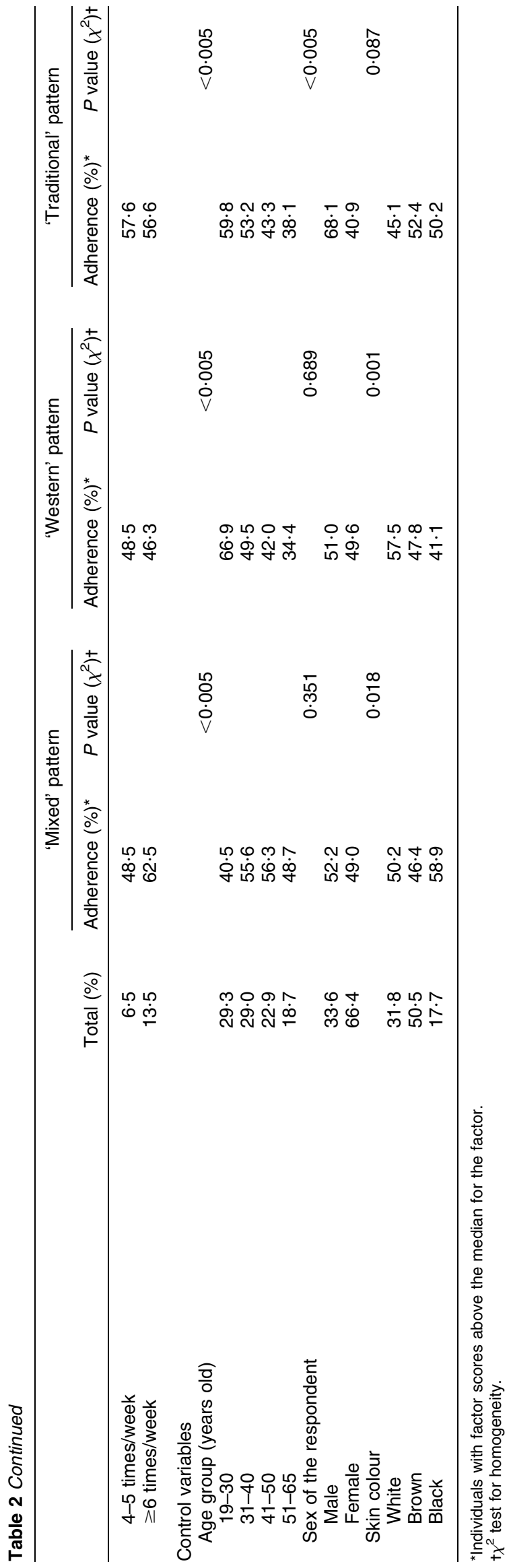

with the average per capita Gross Domestic Product calculated for the country in 2005 (about \$US 4400/year ${ }^{(15)}$ ). Individuals from families with monthly per capita income over half of the official Brazilian minimum wage presented an increment in the probability of choosing this type of dietary pattern even though processed items are more expensive than the foods included in the 'Traditional' pattern, such as rice and beans. Alves et al. ${ }^{(3)}$ observed that women belonging to the $\mathrm{A}$ and $\mathrm{B}$ economic classes, the two most wealthy categories, living in the south of Brazil presented greater adherence to a high-cost dietary pattern that included foods related to the risk of chronic non-transmissible diseases and was based on candy, desserts, sweets, cream, ham, bologna, salami, aged pork loin, industrialized mayonnaise, cheese, fried foods, fast foods, cookies and cakes.

Individuals from families with food insecurity were associated with reduced adherence to the 'Western' pattern, but demonstrated adherence to the 'Traditional' pattern. Additionally, a previous study with this same population observed an inverse association between adoption of the 'Traditional' pattern and BMI (weight/ height $\left.^{2} ; P<0 \cdot 01\right)$ and waist circumference $(P<0 \cdot 01)^{(10)}$. The adherence to the 'Traditional' pattern is considered positive due to the low energy density, the reduced glycaemic index and the good nutritional quality of the rice-and-beans combination, which is also a good source of fibre and $\mathrm{Fe}$. This positive effect reaffirmed findings from a previous study with 2589 adults between 20 and 60 years old residing in the city of Rio de Janeiro, which showed an inverse association between rice-and-beans consumption and the risk of overweight/obesity in both men and women after adjusting for age, physical activity, diet and occupation ${ }^{(13)}$.

Smoking was positively associated with the 'Mixed' dietary pattern, although subjects with college education rejected this eating pattern. Similar results were observed by Pryer et al. ${ }^{(18)}$. Alternatively, McNaughton et al. ${ }^{(19)}$ observed among males that ex-smokers preferred 'Ethnic foods and alcohol' and 'Mixed' patterns and Mishra et al. ${ }^{(20)}$ observed among males that non-smokers also recorded higher scores for the 'Mixed' pattern compared with smokers.

The association between college education and adherence to the 'Mixed' pattern was also observed in previous studies. Lower education was associated with unhealthy eating patterns and high income and education were associated with high scores for healthy patterns ${ }^{(21-23)}$. One analysis conducted among 1026 adult women from southern Brazil found that a lower-cost and high-risk diet was more frequent among women with low educational level ${ }^{(21)}$.

Our sample included a larger proportion of females, which can be partially explained by the great number of households headed by females. Data from the Brazilian Institute of Geography and Statistics indicate that, in the country, $30 \%$ of households are headed by a woman ${ }^{(15)}$, 
Table 3 Hierarchical logistic regression models and dietary patterns in adults ( $n$ 1009) of Duque de Caxias, Rio de Janeiro, Brazil, 2005

\begin{tabular}{|c|c|c|}
\hline & OR & $95 \% \mathrm{Cl}$ \\
\hline & \multicolumn{2}{|c|}{ 'Mixed' pattern* } \\
\hline \multicolumn{3}{|l|}{ Group 3: Variables related to lifestyle } \\
\hline Never smoked & $1 \cdot 00$ & - \\
\hline Ex-smoker & 1.04 & $0.66,1.63$ \\
\hline \multirow[t]{2}{*}{ Current smoker } & 1.58 & $1 \cdot 00,2 \cdot 48$ \\
\hline & \multicolumn{2}{|c|}{ 'Western' patternt } \\
\hline \multicolumn{3}{|c|}{ Group 1: Socio-economic factors } \\
\hline$<0.5(<\$$ US 60.00$)$ & $1 \cdot 00$ & - \\
\hline $0.5-1.0(\$ \cup S 60 \cdot 01-120 \cdot 00)$ & $2 \cdot 31$ & $1 \cdot 54,3 \cdot 48$ \\
\hline$\geq 1 \cdot 0(\geq \$ \cup S 120 \cdot 00)$ & $3 \cdot 00$ & $1 \cdot 81,4.97$ \\
\hline \multicolumn{3}{|c|}{ Group 2: Factors regarding the family and the household } \\
\hline No & $1 \cdot 00$ & - \\
\hline \multirow[t]{2}{*}{ Yes } & $0 \cdot 55$ & $0.36,0.84$ \\
\hline & \multicolumn{2}{|c|}{ 'Traditional' pattern‡ } \\
\hline \multicolumn{3}{|c|}{$\begin{array}{l}\text { Group 2: Factors regarding the family and the household } \\
\text { Family food insecurity }\end{array}$} \\
\hline No & $1 \cdot 00$ & - \\
\hline Yes & $1 \cdot 79$ & $1 \cdot 27,2 \cdot 51$ \\
\hline
\end{tabular}

${ }^{*}$ Controlling for monthly per capita family income, smoking habits, physical activity, alcoholic beverage consumption, age group, sex of the respondent and skin colour. +Controlling for monthly per capita family income, number of household members, presence of children/adolescents, family food insecurity, education, working activity, age group, sex of the respondent and skin colour.

¥Controlling for monthly per capita family income, family food insecurity, presence of children/adolescents, smoking habits, physical activity, alcoholic beverage consumption, age group, sex of the respondent and skin colour.

which is more frequent among those families living in the poorest areas. Since prior analysis showed that there were no variations in dietary patterns according to $\operatorname{sex}^{(10)}$, it is unexpected that these differences could bias our results.

The adoption of an unhealthy eating pattern by economically deprived individuals may be related to the cultural devaluation of foods that compose the traditional Brazilian diet. In contrast, the improvement in purchasing power could signify the possibility of acquiring foods that are socially valued, such as highly processed foods. Unfortunately, some of those items, e.g. sugar-added beverages and cookies, are considered to present risk for the development of non-transmissible chronic diseases.

The epidemiological importance of these findings resides in their contribution to the rationale of intervention programmes and strategies, especially considering the limiting factors to the adoption of healthier eating patterns, such as the high cost of foods like vegetables, fruits, and milk and dairy. Another factor is the need to rescue the cultural and social status of the traditional Brazilian diet and incentivize inclusion of the rice-and-beans combination in the diet of all socio-economic groups.

\section{Acknowledgements}

The study was funded by the Brazilian National Council for Scientific and Technological Development (Conselho
Nacional de Desenvolvimento Científico e Tecnológico CNPq; process \# 503139-2003-3) and the Brazilian National Cancer Institute-Ministry of Health (Instituto Nacional de Câncer-Ministério da Saúde). D.B.C. received a scholarship from the Coordination for the Development of Graduate Personnel (Coordenação de Aperfeiçoamento de Pessoal de Nivel Superior - CAPES) during her Master's studies. The authors declare they have no conflict of interest. D.B.C. was responsible for data treatment, statistical analysis and interpretation; manuscript conception and writing. R.S. was responsible for study conception, data analysis and interpretation; manuscript revision. R.M.V.R.d.A. was responsible for data analysis and interpretation; manuscript conception and revision. R.A.P. was responsible for study conception and supervising; data treatment, analysis and interpretation; manuscript conception, writing and revising.

\section{References}

1. Sieri S, Krogh V, Pala V et al. (2004) Dietary patterns and risk of breast cancer in the ORDET cohort. Cancer Epidemiol Biomarkers Prev 13, 567-572.

2. Jacques PF \& Tucker KL (2001) Are dietary patterns useful for understanding the role of diet in chronic disease? Am J Clin Nutr 73, 1-2.

3. Alves AL, Olinto MT, Costa JS et al. (2006) Dietary patterns of adult women living in an urban area of southern Brazil. Rev Saude Publica 40, 865-873.

4. Fung TT, Rimm EB, Spiegelman D et al. (2001) Association between dietary patterns and plasma biomarkers of 
obesity and cardiovascular disease risk. Am J Clin Nutr 73, 61-67.

5. Perozzo G, Olinto MT, Dias-da-Costa JS et al. (2008) Association between dietary patterns and body mass index and waist circumference in women living in southern Brazil. Cad Saude Publica 24, 2427-2439.

6. Sichieri R, Castro JF \& Moura AS (2003) Factors associated with dietary patterns in the urban Brazilian population. Cad Saude Publica 19, Suppl. 1, S47-S53.

7. Cai H, Zheng W, Xiang YB et al. (2007) Dietary patterns and their correlates among middle-aged and elderly Chinese men: a report from the Shanghai Men's Health Study. Br J Nutr 98, 1006-1013.

8. Correa Leite ML, Nicolosi A, Cristina S et al. (2003) Dietary and nutritional patterns in an elderly rural population in Northern and Southern Italy: (I). A cluster analysis of food consumption. Eur J Clin Nutr 57, 1514-1521.

9. Wirfalt E, Hedblad B, Gullberg B et al. (2001) Food patterns and components of the metabolic syndrome in men and women: a cross-sectional study within the Malmo Diet and Cancer cohort. Am J Epidemiol 154, 1150-1159.

10. Cunha DB, de Almeida RM, Sichieri R et al. (2010) Association of dietary patterns with BMI and waist circumference in a low-income neighbourhood in Brazil. Br J Nutr 104, 908-913.

11. Neumann AICP, Martins IS, Marcopito LF et al. (2007) Padrões alimentares associados a fatores de risco para doenças cardiovasculares entre residentes de um município brasileiro. Rev Panam Salud Publica 22, 329-339.

12. Marchioni DM, Latorre Mdo R, Eluf-Neto J et al. (2005) Identification of dietary patterns using factor analysis in an epidemiological study in Sao Paulo. Sao Paulo Med J 123, 124-127.

13. Sichieri R (2002) Dietary patterns and their associations with obesity in the Brazilian city of Rio de Janeiro. Obes Res 10, $42-48$.
14. Ministério da Saúde Brasil (2006) Guia Alimentar para a População Brasileira: Promovendo a Alimentação Saudável. Brasília: Ministério da Saúde.

15. Brazilian Institute of Geography and Statistics (2000) Demographic census. Rio de Janeiro, 2000. http://ibge. gov.br/home/estatistica/populacao/censo2000/default_familias. shtm (accessed April 2008).

16. Sichieri R \& Everhart J (1998) Validity of a Brazilian food frequency questionnaire against dietary recalls and estimated energy intake. Nutr Res 18, 1649-1659.

17. Cattell R (1966) The scree test for the number of factors. Multivariate Behav Res 1, 245-276.

18. Pryer JA, Nichols R, Elliott P et al. (2001) Dietary patterns among a national random sample of British adults. J Epidemiol Community Health 55, 29-37.

19. McNaughton SA, Mishra GD, Stephen AM et al. (2007) Dietary patterns throughout adult life are associated with body mass index, waist circumference, blood pressure, and red cell folate. J Nutr 137, 99-105.

20. Mishra GD, McNaughton SA, Bramwell GD et al. (2006) Longitudinal changes in dietary patterns during adult life. Br J Nutr 96, 735-744.

21. Lenz A, Olinto MT, Dias-da-Costa JS et al. (2009) Socioeconomic, demographic and lifestyle factors associated with dietary patterns of women living in southern Brazil. Cad Saude Publica 25, 1297-1306.

22. Mullie P, Clarys P, Hulens M et al. (2010) Dietary patterns and socioeconomic position. Eur J Clin Nutr 64, 231-238.

23. Kesse-Guyot E, Bertrais S, Peneau S et al. (2009) Dietary patterns and their sociodemographic and behavioural correlates in French middle-aged adults from the SU.VI. MAX cohort. Eur J Clin Nutr 63, 521-528.

24. Pérez-Escamilla R, Segall-Corrêa AM, Kurdian Maranha L et al. (2004) An adapted version of the US Department of Agriculture Food Insecurity module is a valid tool for assessing household food insecurity in Campinas, Brazil. J Nutr 134, 1923-1928. 